\title{
PROGRESO Y TRADICIÓN EN LA IGLESIA POSCONCILIAR DE LEÓN
}

POR

\author{
GERARdo FERNÁNDE $Z$ FERNÁNDEZ
}

\begin{abstract}
RESUMEN
Estudio de la evolución de la diócesis leonesa durante la época en la que es regida por Luis Almarcha Hernández, época en la que se produce una cierta contestación ante algunas de las disposiciones que se adoptan sobre el clero.
\end{abstract}

\section{Arstract}

Study of the evolution of the Leon diocese during Luis Almarcha Hernández era. In this moment is produced a certain answer againts the arrangements that are adopted on the clergy.

En los años de la posguerra, la Iglesia espafiola había cumplido la función de interiorizar en las conciencias el orden social impuesto por los vencedores y, dada su condición privilegiada, ejercía también el papel de una suave oposición política, en defensa de sus propios derechos y de los derechos de otros colectivos con menos posibilidades 1 . Pero, a partir de los af́os sesenta, la sociedad española se ve afectada por el fenómeno de la contestación contra el régimen político, atizada por los sectores más inquietos como eran los obreros y los estudiantes. La Iglesia la sufrirá en su interior, de mano de los movimientos

\footnotetext{
I Álvarez Bolado (1976), J. Georgel (1970), Ruiz-Rico (1977), Pérez Diaz (1993).
} 
especializados de Acción Católica y de buena parte del clero², por el régimen de alianzas y privilegios mutuos que mantenía con la autoridad civil y por el autoritarismo en el gobierno diocesano.

El presente trabajo abarca los años inmediatamente posteriores al Concilio Vaticano II, coincidentes con el final del amplio y dinámico pontificado de D. Luis Almarcha Hernández ${ }^{3}$, aunque deficitario en sensibilidad para con los sacerdotes. La exposición se centra en el análisis de los hechos de contestación $y$, en segundo lugar, en la reacción institucional ante los mismos.

\section{RuPtURA DEL ESTLLO NACIONAL-CATOLICO}

Podemos distinguir dos tipos de contestación en la diócesis leonesa: el de una pastoral de encarnación, propia del ámbito rural de Zotes del Páramo y del minero de Santa Lucía, y el de la denuncia sistemática, más estructurada y basada en el análisis de los hechos, propia de la ciudad.

\section{a) Pastoral de encarnación}

La contestación leonesa tenía en común con la nacional la sustitución de la imagen sacral del cura, dedicado a los ritos sagrados, distinto y distante de los demás y, ante todo, obediente a la jerarquía, por otra de compromiso con el esti-

\footnotetext{
2 Ver: F. Urbina (1972), Guerra Campos (1989), F. Blázquez (1991), Murcia (1995), F. Montero (1987 y 1990).

${ }^{3}$ «S. E. Rvdma. Dr. D. Luis. Almarcha Hernández, Conde Colle y Señor de Las Arrimadas y Vegamián, etc.n, habia sido consagrado Obispo de León en su ciudad natal de Horihuela el 24 de septiembre de 1944 y accedía al cargo de procurador en Cortes, sucediendo a su predecesor, D. Carmelo Ballester. En 1945 crea el «Consejo de Estudios e Investigación San Isidoro» para el estudio de las Fuentes filológicas de los Archivos de León y la formación de un Registro y un Archivo documental, etc. Dentro de ese Centro creó la «Cátedra de San Isidoro» para estudiar su doctrina y su época y para la formación de investigadores en Paleografia Arqueología y Bellas Artes. En 1947 fundó la revista «Estudios Leoneses», órgano de las actividades culturales del Centro. El 25 de octubre de 1948 toma posesión de la Asesoria Eclesiástica Nacional de Sindicatos, y el 10 de enero de 1952 el Jefe del Estado le concede la Gran Cruz de la Orden de Cisneros «en atención a sus trabajo de siempre en el orden social y cooperativo y a la labor desarrollada al frente de la Asesoría Nacional de la Organización Sindicaly. En 1954 crea la «Fundación Virgen del Camino» e inicia la construcción del santuario del mismo nombre. En 1955 funda la revista "Colligite» y en 1959 crea el "Centro Superior de Estudios Teológicos» en el Seminario Mayor, afiliado a la Universidad Pontificia de Salamanca. En 1961, como respuesta a la petición de las Autoridades leonesas, le fue concedida por el Jefe del Estado la Gran Cruz de Alfonso X el Sabio «por los afanes del Dr. Almarcha por la cultura de León». Dejó su cargo en 1970. Los datos están tomados del Boletín Oficial del Obispado de León.
}

Actas del I Congreso de Historia de la Iglesia y el Mundo Hispánico Hispania Sacra, 52 (2000) 
lo de vida de los fieles y de sus intereses, dando prioridad al trabajo en equipo y a la idea de participación.

La línea misional contrastaba con la pastoral conservadora y de cristiandad, mantenida tradicionalmente por el Obispado. Ahora, las iglesias servían no sólo para los actos cultuales sino también para reuniones vecinales en las que se planteaban problemas de interés público, $y$ de tipo laboral. Los aranceles de bautizos, bodas y entierros, poco significativos en la economía parroquial y en la personal y relacionados con la idea de Iglesia burocrática y de clérigo avaro, quedaron suprimidos. Y otra práctica común en las empresas entonces, el adoctrinamiento cristiano masivo y de evasión de los problemas concretos económico-sociales, propios de aquella época nacional-católica, fue rechazada: la Empresa Hullera Vasco-Leonesa de santa Lucía, como todas hacían entonces, facilitaba predicadores, que todos los años sermoneaban los ejercicios espirituales a los obreros en boca-mina y, al final de la tanda de charlas, reunian a los sacerdotes del contorno para que los confesaran allí y así cumplieran con Pascua.

Pero lo más grave de aquella acción pastoral era su base ideológica: la «Nouvelle Théologie» y la doctrina conciliar, leídas desde el punto de vista del compromiso con el mundo del trabajo. Un compromiso que era liderado por los movimientos epecializados de Acción Católica, JOC y HOAC, cuyos métodos de acción entre los obreros eran la toma de conciencia de su situación sociolaboral, el juicio sobre la misma desde las exigencias de justicia, y la actuación encaminada a la mejora de aquellas condiciones; pero seguidos de forma semiclandestina, dada la oposición de Mons. Almarcha a tales movimientos. A esta acción dedicaron los sacerdotes, especialmente el párroco de Santa Lucía, sus esfuerzos, sin descuidar su la función cultual sacerdotal ${ }^{4}$. Y no se detenía ahí sino que abarcaba también el ámbito de la enseñanza. Ya en 1963, el Colegio de monjas de Santa Lucía, que impartía la EGB, se amplió para que las chicas cursaran estudios de Bachillerato, por interés de los padres, en orden a que no vieran cerrado el horizonte de sus vidas exclusivamente al que les ofrecía la mina. Pero los chicos se veían forzados a seguir la Enseñanza Profesional en el colegio de Santa Lucía, regido por los Salesianos, que después se trasladó a la Robla. También para ellos pedían los padres la posibilidad de hacer Bachillerato. Pero, como la coeducación era ilegal, fue necesario pensar en otro centro. Comenzaron las actividades ecadémicas el año 1965 con normalidad; pero no

4 «D. Eladio, lleva a cabo su cometido con tesón y continuo esfuerzo visitando en sus propios domicilios a sus feligreses (...), a los que con su asistencia y palabras de promesa logra convencer. También les habla de la orientación de sus derechos laborales, haciéndoles ver las reducidas remuneraciones que perciben en razón con el trabajo tan penoso y expuesto que tienen como mineros.s Nota informativa del SIGC de 22 de marzo de $1967, A G A$, Caja 567. 
agradaba a la empresa la influencia de los sacerdotes en la educación. Aprovechando la ocasión de las dificultades económicas, se hizo cargo de la subvención a cambio de la titularidad del Centro. Al finalizar el curso 1969-1970, despide al Director el 2 de julio y confía la gestión a los HH. Maristas de León. A pesar de las asambleas convocadas por los sacerdotes y por muchos de los padres de alumnos para llegar a una solución de mutuo acuerdo, la Empresa no se movió de su posición: quería solamente hacer una dirección mejor y los $\mathrm{HH}$. Maristas ofrecían esa garantía ${ }^{5}$.

\section{b) Contestación sistemática}

Puntos centrales de la contestación fueron la situación del clero, la de los seminarios diocesanos, la del apostolado seglar, y la actuación del Obispo y de la Curia. Nos sirven de orientación para el trabajo los distintos informes sobre el estado de la diócesis, elaborados por aquel entonces ${ }^{6}$.

Oficialmente, el clero leonés era sacrificado, entregado totalmente a su quehacer ministerial, etc. No obstante, la realidad era muy otra. Se vivía en la Diócesis una fuerte tensión y competitividad entre bloques, que venían a reflejar el panorama a nivel nacional ${ }^{7}$, tal como los trabajos de la Asamblea Conjunta pusieron de manifiesto. Pero en León esos porcentajes experimentaban pequeñas variaciones en cuanto que, por la parte progresista, el porcentaje llegaba solamente a $16 \%$ y, por la conservadora, al $19 \%$. En este bloque había otra corriente a destacar, el Instituto Secular Sacerdotal de San Isidoro, cuyo centro estaba en la colegiata del mismo nombre.

Nada había que hiciera reprochable al Instituto ante los demás sacerdotes diocesanos, limitado al cabildo isidoriano; pero cundía la alarma cuando se extendía al clero diocesano, y esa expansión era valorada como discriminatoria y como

\footnotetext{
5 Las fuerzas de la Guardia Civil de la Comandancia de León intervinieran a fin de impedir la llegada de los sacerdotes a las reuniones convocadas en el Colegio y para prohibir la convocada por aquéllos en la iglesia. La entrevista con los maristas para que suspendieran el «si» a la empresa tampoco tuvo éxito. Ellos dijeron que no estaban interesados más que en las cuestiones de educación y la decisión estaba tomada. E. FERNANDEZ, entrevista, 4-6-1994.

${ }^{6}$ Cuatro son los fundamentales: INCO 1968, realizado por ocho sacerdotes (tres profesores del seminario y cinco párrocos de las más variadas zonas de la diócesis). ESTIN 1969, realizado por dos exprofesores del Seminario Mayor y dirigido al Nuncio (Archivo, Francisco Fontecha). INSE 1970, de primeros de 1970, obra de un equipo que se define como "seglares responsables", algunos de los cuales tenian contactos con los movimientos especializados de AC, o provenían de «Los Luises» y por un grupo que se integraba en el Secretariado Gitano de León, dirigido por José-Luis Cantón de Celis. INCAR, obra de un grupo de sacerdotes, y enviado al Director de la Comisión Episcopal de Seminarios de la CEE. (Archivo, B. Domínguez).
} 
promoción personal para los afiliados, a costa de las posibilidades de los no isidorianos. Y cundía, sobre todo, cuando los canónigos de San Isidoro iban ocupando los puestos de más responsabilidad en la Diócesis, bajo la especial protección del obispo Almarcha, que veía en él el instrumento ideal para la formación y cultivo de la espiritualidad sacerdotal y para el apostolado en general ${ }^{8}$.

Objetivamente había razones para la protesta cuando el grupo isidoriano aparecía como elitista y, en una diócesis de escasa posibilidades de promoción personal, la distribución de cargos no respetaba la igualdad de oportunidades. Subjetivamente, tanto isidorianos como no isidorianos hacían lo que creían mejor para el bien de la Diócesis. La crítica que se hacía de esta situación, valorada como de privilegio manifiesto, era fuerte: «apadrinan cualquier actividad diocesana, aunque no sea obra de ellos, no la realicen ni tengan las mejores cualidades para hacerlo", y se derivaban unas consecuencias graves: «recelo entre los sacerdotes, la evasión de la misión por parte de aquellos que son alejados de sus puestos (que pasan a los isidorianos) y el sentimiento extendido de que en León no se puede vivir como simple sacerdote sin condenarse a la ineficacia y vejación». De cara al futuro se decía que el Instituto Isidoriano será «motivo de división y recelos mutuos entre los sacerdotes diocesanos», un «obstáculo para la pastoral de conjunto, un corsé para el nuevo Obispo que tendrá que aceptar el sistema de escalada de puestos, negación de otros valores y personas» en caso de que fueran aprobados los Estatutos. En una pastoral de conjunto prevalecerían los intereses del instituto sobre los de la diócesis?.

También el Opus Dei se encontraba en fase de expansión, y había colocado un profesor en el Seminario Menor y tres en el Mayor, razón por la que sacerdotes de esta obra dirigían los ejercicios espirituales o los retiros a los seminaristas. Era el punto de contacto para la intensa campaña que llevaron a cabo

\footnotetext{
7 Un 60\% del clero diocesano aceptaba, en general, los cambios exigidos por el Concilio Vaticano II segín las directrices del episcopado. Un 20\% más o menos, de Opus Dei y de la Hermandad Sacerdotal Espaffola principalmente, se oponía a los mismos. Y el otro $20 \%$ los estimaba insuficientes. Vicente Enrique y Tarancón, entrevista en Villareal, 4-XII-1991.

${ }^{8}$ En la Curia diocesana ocupaban los cargos de Delegado de Ensentianza, de Pastoral y del Clero; en los seminarios ocupaban el Rectorado, Vice-Rectorado, Dirección Espiritual, Prefecto de té́logos y varias plazas de profesorado. Dirigtan el movimiento de Ejercicios Espirituales, de Misiones Parroquiales, de la Unión diocesana de Apostolado Seglar, de la Junta Diocesana de Acción Católica, de Cursillos de Cristiandad y de la Adoración Nocturna. Cfr.: Guía de la Iglesia en León, León 1971, pp. 66-132. Un canónigo de San Isidoro acumulaba cinco cargos diferentes. Cfr. Guía General de la Diócesis, 1964.

${ }^{9}$ Las citas pertenecen al Informe sobre el Instituto de San Isidoro de león (Espafia), de 27-II-1970 (INFISSI) pp. 3-4, presentado ante la santa Sede con el fin de que no fueran aprobados sus estatutos. No tiene firma y es obra de un sacerdote que dice trabajar solo, aunque cree que recoge la opiniones de la mayor parte del clero de la diócesis (NB, p. 9).
} 
entre los sacerdotes jóvenes y entre los seminaristas, invitándoles a convivencias, retiros, etc., donde cada uno de los asistentes era pormenorizadamente controlado y persuadido. Aprovechando el período de crisis en el Seminario Mayor, lograron captar varios seminaristas. Cuando Mons. Larrea tomó la decisión de cortar esta corriente, algunos de los más adictos se fueron al Seminario de Toledo, en cuya diócesis eran bien acogidos por el Arzobispo. Nada dicen los distintos informes acerca de la Hermandad Sacerdotal espantola. Cuando se ponen en marcha los equipos para la preparación de la Asamblea Conjunta y en su fase diocesana especialmente, se pone de manifiesto la pugna de los distintos sectores por alcanzar el control de los distintos órganos de la misma ${ }^{10}$.

Los informes denuncian, en primer lugar, la situación incómoda que vivía el clero. La mayoría de los jóvenes, en microparroquias, conscientes de no tener nada que hacer; $y$ un elevado número en la ciudad, con escasa dedicación pastoral y reducida a las actividades tradicionales. Contaban también los problemas de las grandes diferencias de mentalidad y de ingresos, y la falta de desarrollo personal integral a tono con los tiempos. El resultado de esta situación de cara a la diócesis era un clero empobrecido, instalado en su sacerdocio, alejado de los jóvenes y de los que no frecuentaban las iglesias, conformista y evadido de los problemas de la sociedad. Sólo una minoría aparecía con ansia renovadora y luchando contra las estructuras anquilosadas; pero su eco era escaso porque chocaban contra las estructuras inmovilistas y se les marginaba como urevolucionarios y desobedientes).

Los seminarios, especialmente el Mayor, son objeto de un detenido examen, debido a la crisis que venía padeciendo y que estallo en los cursos 1969-1971. «Padecía una crisis profunda de crecimiento, aplastado externamente por moldes, vigilancia, miedo, e internamente, por la angustia (...). Sin camino alguno para un diálogo, la solución se ve a favor de un autoritarismo que deje muy disminuido el número del Seminario Mayor o, más grave aún, animado por los menos dotados». Se denunaciaba el aislacionismo interior, porque se lo consideraba sólo como obra de los formadores, y el exterior, porque se mantenía cerrado a otros seminarios y a otras experiencias, fiel a la consigna de Almarcha de: «no tienen nada que aprender fuera». Se consideraba a los seminaristas, como carentes de preparación humana y de personalidad, ignorantes de las realidades externas, de formación intelectual pobre y desfasada y de una religiosidad falsa y superficial. Se denunciaba también, como causa de la crisis, la falta de preparación y especialización de los educadores y profesores, escogidos de entre los «fieles» al sistema, mientras que los (innovadores» eran marginados.

${ }^{10}$ La relación de fuerzas definitiva en la asamblea propiamente dicha fue de $74 \%$ moderados, $21 \%$ conservadores y $5 \%$ progresistas.

Actas del I Congreso de Historia de la Iglesia y el Mundo Hispánico Hispania Sacra, 52 (2000) 
El criterio decisorio de uno u otro sentido era el juicio del Rector, único lazo de unión entre Seminario y Obispo ${ }^{11}$.

Si la valoración de la formación era grave, los hechos lo eran aún más. El 5 de septiembre de 1966, tres profesores del Seminario Mayor entregan al Obispo un estudio en el que analizaban la situación del mismo y proponían mejoras de tipo académico y disciplinar. Dos de ellos pagarían caro su atrevimiento. E1 único resultado del mismo fue la fulminante destitución de uno de los profesores de Teología, el Magistral de la Catedral, el otro pemanecía en su puesto tras pedir disculpas, y la reducción a un mínimo de clases para el profesor de Filosofia. Para la institución, el resultado fue «la concentración de pleno poder y autoridad en el Rector, abarcando, incluso, el aspecto docente por encima del Prefecto de Estudios (cargo que desapareció) y del Claustro de Profesores. Toda función del Seminario Mayor debería ser controlada y dirigida por el Recton ${ }^{12}$. Ningún sentido tenía en aquel sistema la colaboración activa y responsable; la obediencia era simple pasividad y nada más. Quienes pretendían otra cosa eran revolucionarios y estorbaban al sistema.Y, si se usaba tal violencia con los profesores, mayor era la ejercida contra los alumnos, recurriendo a las expulsiones fulminantes e incluso al uso de métodos policiales, como la incomunicación practicada el 6 de febrero de 1968 contra tres alumnos de Teologia, que dieron lugar a conatos de abandono del Seminario por parte de sus compafferos ${ }^{13}$.

En cuanto al apostolado seglar, parecía en octubre de 1968 que se iniciaba una nueva etapa, tras una reunión de los representantes del Secretariado Gitano con el Obispo y algunos miembros de la Curia, en la que se creó la UDAS (Unión Diocesana de Apostolado Seglar), para coordinar todos los movimientos de apostolado seglar. De nada sirvió porque solamente se reunió en dos ocasiones.

Desde la Curia se apoyaban los movimientos conservadores, como la AC clásica, dirigida por personas de la alta sociedad leonesa y limitando su acción a las funciones catequéticas y caritativas de las parroquias, o como los Cursillos de Cristiandad con un equipo de seis sacerdotes y ocho seglares ${ }^{14}$. Los criterios de acción no podían ser otros que los de «beneficiencia» cuando los seglares y sacerdotes más dinámicos pensaban en la "promoción social»"

La crítica caía de lleno sobre el sistema piramidal feudal vigente en la diócesis, en cuya cumbre estaba entronizado el Obispo y cuyas reglas de gobierno, en el sentido descendente, se fundamentaban en el favor y, en el ascendente, en el

I INCO 1968, 5-7; INSE 1970, I. 3.

12 ESTIN 1969, 16-20; Cfr. INCO 1968, 7.

13 INCO, 1968, Apéndice 1 y 2, A y B, en G. FeRNáNDEZ (1999), nota 153.

14 INCO 1968. V), 2); INSE 1970, II, 2, y III, 2.

is Secretariado Gitano en León, Archivo, Benjamin Dominguez. 
servilismo. Según los informes, el Obispo y la Curia diocesana daban más importancia al Código de Derecho Canónico que al Evangelio, impedían la acción pastoral misional y eran indiferentes a los problemas personales ${ }^{16}$.

\section{REACCIÓN INSTITUCIONAL}

No podía pasar desapercibida para el Obispado aquella serie de actuaciones que suponían al más rotundo rechazo a un estilo de gobierno político y religioso consagrado como ideal ${ }^{17}$. En su respuesta pondrá de manifiesto tanto su alianza con el poder civil como su autoritarismo.

\section{a) La alianza por el poder}

Se puso de manifiesto especialmente en su acción frente a los problemas de la zona minera. La metodología de HOAC y de JOC era especialmente irritante para el obispo de León por su condición de parlamentario y de asesor nacional de sindicatos. Para la Empresa, el desagrado venía de su lógico interés por evitar toda clase de conflictos. Y conflictiva era para ella toda asociación obrera, fuera del marco del sindicato vertical, y toda inicitaiva que perturbara el equilibrio del sistema. De ahí, la sospecha continua sobre las actividades de los sacerdotes y de los movimientos que las animaban bajo la capa de las Hermandades del Trabajo. Por todo ello, el Obispado no podia dejar de intervenir, y lo hizo, salvaguardando no el bien de los sacerdotes y de una acción pastoral más eficaz desde el punto de vista evangélico, sino el orden sociopolítico establecido y sostenido por el Regimen, por la Iglesia, y por las empresas mineras. Las tres fuerzas aparecerán actuando de común acuerdo.

Ya había actuado contra el Párroco de Pola de Gordón, acusado por los tradicionales falangistas, y el Obispado no le ofreció otra posibilidad que la de irse de capellán de emigrantes. Tocaba el turno ahora al párroco de Santa Lucía, que se signifiçaba como el más activo del grupo. Así las cosas, y sin haber tenido lugar petición alguna ni cambio alguno de impresiones, el 13 de enero de 1970, recibe Eladio una carta del Obispado con la orden de traslado a la parroquia de

\footnotetext{
16 INCO 1968, 14-17 y 21-24; INSE 1970, l.-2.

${ }^{17}$ Ecclesia había dicho "Quizá, desde hace siglos, nunca tuvimos los católicos españoles manos más libres para aplicarlas al trabajo apostólico con todas las garantías humanas de éxitom (XII, 1953) y Colligite, después de hacer un recuento de las realizaciones religiosas de posguerra: «Al terminar nuestro número especial el lector sentirá una sensación de satisfacción y bendecirá al Señon $(20,1959,25-$ 55).
}

Actas del I Congreso de Historia de la Iglesia y el Mundo Hispánico Hispania Sacra, $52(2000)$ 
San Cipriano del Condado, y de tomar posesión antes del 1 de febrero. El día 15 de enero trata, en vano, de entrevistarse con el Obispo, que se niega a recibirle. Como reacción, los compafferos de equipo se ponen en comunicación con otros sacerdotes de diversos arciprestazgos y de la ciudad, y el día 22 se reúnen y redactan un duro documento, que fue firmado después por un total de ventisiete sacerdotes, y presentado al Obispado con la advertencia de que, si no había contestación, tomarían posturas más serias ${ }^{18}$. También el pueblo de Santa Lucía, que fue tomando conciencia del traslado de su Párroco,y decidió pasar a la acción, redactando tres escritos; dos de particulares y uno de la Junta Vecinal, reuniendo 919 firmas en total.

Lo más indignante, tanto para sacerdotes como para vecinos, fue que los escritos de unos y de otros, dirigidos al Obispo, fueron entregados a las autoridades civiles. Por esta razón, el día 28 de enero, se presentó en el pueblo el Teniente Coronel de la Guardia Civil de León para interrogar largamente a los redactores de los escritos y amenazar a los máximos responsables y a los firmantes. Aparte de estas medidas populares, el Gobernador Civil citó el día 27 al Alcalde de la localidad, que regresó convencido de que Eladio era comunista, la acusación más grave en el franquismo. Prueba de la connivencia entre Obispado y Gobierno Civil de León fue la nueva cita, el día 30, en la que comunicó al Alcalde y a la Junta Vecinal que Eladio era un elemento peligroso y que en el Obispado estaba considerado como mal sacerdote; pero que, dada la inoportunidad del momento por las huelgas de Asturias, no se iba a llevar a cabo su traslado.

Mientras, el Obispado enviaba, como única señal, una carta que no respondía al problema sino que constitufa una amenaza ${ }^{19}$. Por eso, ante la respuesta intimidatoria y ante el hecho de la entrega de los escritos a la Policía, toman la decisión, el día 29, de enviar una delegación a la Nunciatura con un escrito de denuncia $^{20}$. El día 2 febrero recibió Eladio la comunicación del Obispado, anu-

18 «Deliberadamente se trata de destruir toda posible labor de equipo con orientación misionera (...) nuestros superiores se atan servilmente a las exigencias de los altos mandos de la Empresa Hullera Vasco-Leonesa S. A.». Y califican la medida como uun caso más en la serie demasiado larga de sacerdotes que, en estos últimos afios, o se han visto alejados de todo ministerio y de toda percepción económica, o han sido trasladados sin ser oídos, y sin atender, por tanto, a sus circunstancias personales, o no han encontrado en la diócesis la comprensión y la paz para el desarrollo de su sacerdocio, y se han visto forzados interiormente a salir de la diócesis o abandonar el ejercicio ministerial. León, 22 de enero de 1970m. Archivo, E. Femández.

19 «SECRETARÍA-CANCILLERIA DEL OBISPADO DE LEÓN. (...) de acuerdo con lo prescrito en el can. 2399, han sido suspendidos a divinis (...) los Rvdos. St. Dionisio Manga Rodríguez, coadjutor que fue de la parroquia de Cistierna, y Rvdo. D. Ambrosio González Alonso, que fue cura ecónomo de Valle de Vegacervera y doblante en Villar del Puerto (...) y a tenor del canon 2399, el Rvdo. Sr. D. Adolfo Gutiémez Viejo, organista que fue de la Catedralm. Archivo, B. Dominguez.

20 Escrito al Nuncio. Archivo, B. Domínguez. 
lando la orden de traslado y anunciándole la reducción de sus licencias ministeriales a la parroquia de Santa Lucía exclusivamente ${ }^{21}$.

Pero no acababan allí los problemas. Ahora continuaban con los Maristas del Colegio y la chispa saltó el 11 de marzo de 1973, domingo de cuaresma. Comentando el texto evangélico «no es el hombre para el sábado sino el sábado para el hombre», Eladio hizo la aplicación genérica de: «igualmente la parroquia es para el feligrés y lo mismo cabe decir de cualquier institución; una empresa, un ayuntamiento, etc.», lo cual disgustó a los maristas. El domingo siguiente, en la misa de 10, estaba la iglesia muy concurrida, de forma insólita a esa hora: todos los maristas, los directivos de la empresa, la Guardia Civil y más fieles que de costumbre. El evangelio trataba de la subida al monte Tabor y en la homilía intervino el Director del colegio que, seguidamente, abandonó la misa con su grupo. Ya fuera de la Iglesia, el Párroco fue increpado por algunos padres de alumnos. La Guardia Civil tomaba nota minuciosamente ${ }^{22}$. No faltaron, como de costumbre, las denuncias al Gobernador Civil y al Obispo, Mons. Larrea que, siguiendo unos criterios opuestos a los de su antecesor, Almarcha, se desplazó a la zona y mantuvo una reunión con Eladio, con los maristas y con la religiosas en la vecina localidad de La Vid. Llegaron a un acuerdo, pero no a la cordialidad: Eladio no aceptó la proposición del Director del colegio de darse ambos un abrazo en el momento de la paz, en la misa que iba a presidir el Obispo al día siguiente, fiesta de San José: «Cada uno en lo suyo, bien; pero amigos no se puede y el abrazo no lo siento, de verdads $)^{23}$.

Y no sólo quedaban las actuaciones policiales en los informes. Una vez más, Eladio fue protagonista del hecho más doloroso, entendido el término en su sentido más real, residiendo ya en León y desempeñando el cargo de coadjutor en la parroquia de Santa Ana, en cuyos salones se fundó, con su cooperación, el sindicato Comisiones Obreras de León. El historial que arrastraba y su acción social en el nuevo destino, le convirtieron en objetivo prioritario de la Policía. Había sido advertido de que le andaban buscando y, el 12 de noviembre de

21 "En vista de las circunstancias, ordenamos: 1. Queda anulado el nombramiento de traslado a las parroquias indicadas prohibiéndole tomar posesión. 2 . Se abre expediente judicial para proceder conforme a derecho, quedando entre tanto reducidas las licencias ministeriales del Sr. Ecónomo de Santa Lucía a dicha parroquia. Dado en León a veintiocho de enero de mil novecientos setenta. EL OBISPO DE LEÓN». Archivo, E. Femández.

22 Da cuenta de los hechos el mismo Eladio, en la entrevista citada, y coincide con el informe elaborado por la guardia civil: «Don Eladio, por favor le pido que suba al «Monte», explique el Evangelio y nos diga lo que allí aconteció con respecto a la Palabra de Dios (...) verdaderamente no puedo continuar la Santa Misa ni tomar la comunión de sus manos»; y seguidamente abandonó la iglesia. A la salida varios padres de alumnos pidieron explicaciones al sacerdote por la actitud con respecto al colegio, exigiéndole que dejara tranquilo al colegio y que de no ser así se marchase de Santa Lucían. Documento de teletipo, $\sin$ fecha y $\sin$ dirección. $A G A$, caja 567 .

Actas del I Congreso de Historia de la Iglesia y el Mundo Hispánico Hispania Sacra, $52(2000)$ 
1976, consiguieron su objetivo. Había tenido lugar una manifestación en León. Sin acercarse al lugar de la misma, salió hasta el bar-restaurante «El Besugo» para conocer noticias. Al salir del bar, fue reconocido por una pareja de la Policía que, sin más explicaciones ni motivos, le propinó una tremenda paliza, dejándole tendido en el suelo, seimiinconsciente y abandonado a su suerte. Cuando el Obispo trató con Eladio la presentación del caso ante los tribunales, éste tomó la decisión de no denunciarlo. Por esta razón, aunque ocho sacerdotes presentaron un escrito de protesta ante el Gobernador Civil de León pidiendo que se aclarasen las responsabilidades, no tuvo más consecuencias ${ }^{24}$.

Razones también puramente religiosas motivaban las actuaciones policiales contra el párroco de Zotes del Páramo, D. Julio Martínez Redondo. El 7 de marzo de 1974 la Guardia Civil presenta un informe donde se hace constar que D. Julio es "progresista». Ya el 29 de marzo de 1969 se le abrió atestado por fuerzas de la Guardia Civil de Santa María del Páramo, entregado al Juez de Instrucción de La Bañeza por editar folletos'y hojas sueltas, sin autorización para ello y valiéndose de la multicopista del Tele-Club, y de tratar temas sociales en reuniones con jóvenes y en las homilías ${ }^{25}$. El atestado de referencia fue ordenado por escrito del Gobernador Civil al Delegado Provincial del Ministerio de Información y notificado también al Obispo por carta en la que se le daba cuenta de denuncias confidenciales por publicaciones, donde «se vierten ensefianzas o ideas nuevas, consideradas por la mayoría de los feligreses como peligrosass ${ }^{26}$.

\section{b) Autoritarismo eclesial}

Tras las medidas disciplinarias del Obispo contra los profesores que habian osado manifestarle su parecer sobre el Seminario, la Curia siguió haciendo honor a su estilo. La crisis del Seminario fue la ocasión propicia y el motivo, la larga polémica entre sacerdotes de las distintas tendencias, que, una vez jubilado Almarcha, se hicieron pública y notoriamente. Inició el fuego periodístico un editorial de la revista diocesana «Colligite»" ${ }^{27}$, calificado por el Diario de León

\footnotetext{
23 No obstante sí llegó a realizarse el abrazo. «Al decir DAOS FRATERNALMENTE LA PAZ el Provincial de los maristas (...) subió al altar donde se hallaba (el Párroco), dándole un abrazo, por lo que se cree que el antagonismo entre ambos, de momento desaparezca» $A G A$, caja 567.

24 Eladio FernANDEz, entrevista citada. El escrito, en Archivo, Benjamín Domínguez.

25 Informe del SIGC, $A G A$, Doc. 45330, Caja 567.

26 AGA, A-12-4158, N 11. Caja 567.

27 «Vemos con desolación la realidad de los seminarios en franca descomposición (...). El malestar ha estallado y surge al exterior en forma multiplicada de rebeliones, protestas, planes, dimisiones, manifiestos, acusaciones, huelgas y cierres (...), domina un clima de disconformidad, de crítica (...). A1 
como lleno de clarividencia y objetividad, mientras el Delegado Diocesano de Educación lo censuraba una sinrazón ${ }^{28}$. Analizaba las causas de la crisis y acusaba en primer lugar a la estructura del seminario clásico, cuyos recursos y métodos consideraba absolutamente desfasados, y proponía la necesidad de seguir la orientación del Concilio y de los documentos posteriores del episcopado español, y de encomendar la tarea educativa a nuevas personas, «que hagan de aquel recinto un centro educativo sacerdotal en una convivencia y una estancia grata, feliz, amada, inolvidable». El problema tuvo eco nacional en el semanario Vida Nueva, que lo valoró como fruto de una línea un tanto trasnochada de actuación al tiempo que proponía una línea de diálogo entre todas las partes, del que pudieran salir medidas aceptables para todos ${ }^{29}$.

Pero las medidas no fuero éstas. El «Informe al clero diocesano sobre la situación del Seminario Mayon', de 25 de enero de 1971, culpaba de la crisis a los seminaristas y ninguna responsabilidad reconocía por parte de los formadores ni del sistema como tal. En segundo lugar daba cuenta de que el Vicario había decidido nombrar una comisión y había tomado unas resoluciones concretas para salir de la crisis ${ }^{30}$. El informe, un balón de oxígeno que permitía prolongar aquella situación, iba acompañado de las «Normas Fundamentales de la Formación Sacerdotal», que eran la base para realizar «una prudente selección» y «una seria prueba». Salvo una ligera apertura, las Normas Fundamentales eran la continuación de la misma situación anterior e idéntico criterio inspiraba las «Normas Prácticas para el Profesorado» $\}^{31}$.

El informe y las disposiciones oficiales fueron el motivo de la polémica inicida por una carta del Magistral de la Catedral en la que criticaba que no tratase las causas de la inquietud seminarística, ni la incompetencia de los formadores, y que culpase de la crisis a "ciertas influencias externas», que no explicase las medidas tomadas, ni las irregularidades que presentaba la constitución de la comisión. En segundo lugar, más novedoso, hacía una denuncia de dos grupos

no encontrar cauce moral estos estados de ánimo, las cosas están empeorando bruscamente», Colligite, 63 (1970) 3-17.

${ }^{28}$ En el artículo «Seminarios o fantasmas?» decia: «Los que pisamos los pasillos de nuestros seminarios actuales no podemos conocer en ellos el seminario que se nos pintay. Diario de León, 29 y $31-\mathrm{X}-1970$.

29 Vida Nueva 770,1971 , p. 11.

30 Las decisiones eran: 1. Promulgar unas 'Normas Fundamentales de la Formación Sacerdotaly con base en los documentos de la Santa sede y de la CEE; 2. Designar el equipo de formadores; 3. Aceptar la renuncia de algunos formadores; 4 . Recordar a formadores y profesores la necesidad de trabajar unidos; 5 . Invitar a los alumnos a una reflexion eseria y leal» sobre las Normas Fundamentales. BOOL 1-2, 1971, pp. 3-6.

31 Estas Normas, que se limitaban a recomendar que no salieran a la luz pública los problemas, a evitar la desautorización de los profesores, y a recomendar dedicación y puntualidad, aparecieron publicadas en una separata no inserta en el Boletín. (Archivo, B. Domínguez).

Actas del I Congreso de Historia de la Iglesia y el Mundo Hispánico Hispania Sacra, 52 (2000) 
sacerdotales que, según el autor de la carta, eran los responsables de la crisis ${ }^{32}$. Al margen -decía- quedaba el "clero silencioso» y, en consecuencia, afirmaba que la fórmula rehabilitadora propuesta oficialmente seguiría siendo la misma de la «insuficiencia doctrinal e ideológica», que facilitaba la "fuga de cerebros» $y$ ofrecía a los seminaristas la alternativa de aguantar $o$ abandonar.

Inmediatamente hubo respuesta. La primera, del Delegado Diocesano de Educación y Ensefianza, que dejaba de lado la argumentación para entrar en el enjuiciamiento del autor ${ }^{33}$, y la otra, de tono más ecuánime, aparecía en el Boletín del Obispado, firmada por el Vicario, pero ambas del mismo origen. Salía al paso de las denuncias más graves del Magistral, como la concentración de poderes en el Rector y la irregularidad de la comisión de crisis tanto en su constitución como en su funcionamiento. Por último, daba a conocer el nuevo equipo de formadores internos, cuyos miembros, excepto uno, figuraban todos en el anterior ${ }^{34}$.

Aún volvió el Magistral de la Catedral a publicar otra carta el 22 de febrero en la que daba por terminada definitivamente su intervención sobre el Seminario. Se reafirma en lo expuesto en la primera, y asegura que el problema del Seminario seguía en pie. «Los sacerdotes y fieles turbados y desorientados. No por mi escrito sino por la solución adoptada» ${ }^{35}$.

32 «En la solución del problema del Seminario (...) como en la marcha del mismo en los últimos tiempos, han actuado dos fuerzas, podía llamarlas ugrupos de presióny; la isidoriana y la del Opus, en cuyas manos ha estado la formación de los alumnos. Por ello, quizá pudiera llegarse a una conclusión: el estado cático del Seminario revela el fracaso de esas fuerzas como formadoras de seminaristas, y la comisión y los documentos son también fruto de tales grupos. X, con ellos, adelanto mi opinion, se integrará «su» equipo de formadores para esta nueva etapa». La carta, fechada el 31-I-1971, terminaba con una NOTA: «He remitido la información y documentos al Sr. Nuncio y al Presidente de la Comisión de Seminarios». Archivo, Benjamín Dominguez.

${ }^{33}$ «(...) La carta que Vd. se ha encargado de difundir tan extensamente, bien se podría titular "nuevo capitulo de una larga serie de resentimientos» (...) Manifiesta en muchos casos una absoluta ignorancia, una malévola falsificación de los datos del problema del Seminario.(...) Es una lástima que se dedique Vd. a sembrar la cizaña, porque el que siembra la cizaña es «inimicus homon.(...) Vd. sí que necesita «abrir los ojos», pues su refinada soberbia, tan acreditada por cierto, se los tiene bien cerrados». Archivo, B. Domínguez.

${ }^{34}$ El nuevo equipo quedaba reducido. Había salido el Rector, y el antiguo Vicerrector quedaba en funciones de Rector; los dos directores espirituales habían sido sustituidos por uno procedente del Seminario Menor; continuaba como formador el que lo era de filósofos en el anterior equipo; a los tres se añadian un mayordomo y un interventor, que ya lo eran anteriormente.

${ }^{35}$ Se reafirma en la concentración de poderes absolutos en el Rector, obra de Mons. Almarcha en 1966, confirmada en 1968, en la irregularidad en la constitución de la Comisión y en su funcionamiento. $Y$ vuelve a denunciar «el bloque de i 5 in en la Comisión, cuatro del grupo de Sn. Isidoro y uno del Opus Dei, y al equipo de formadores, mayoritariamente de los mismos grupos. Y señala que nada decian los informes de la Vicaría acerca de la cuestión de la insuficiencia ideológica y doctrinal, la fuga de cerebros entre los sacerdotes y seminaristas, ni la existencia de los grupos de presión. Archivo, B. Domínguez. 
Esta política habia sido una constante desde los inicios el mandato de Almarcha en la diócesis. El Sínodo Diocesano de 1957, tras el trabajo entusiasta de las distintas comisiones, resultó, al final, una aprobación de los anteproyectos presentados por los hombres de confianza del Obispo, cercenando así el sano pluralismo que se había manifestado entre el clero. Realmente, «el Espíritu Santo había soplado fuerte", según se decía, en favor de la unidad diocesana, la impuesta por el Obispo y la Curia. La expresión «El Obispo no dialoga: escucha y juzga», reflejaba meridianamente el distanciamiento total entre él y los sacerdotes.

No podía merecer mejor valoración, por tanto, la Curia diocesana. Los sacerdotes la evitaban en lo posible. Estaba, pues, desprestigiada por sus miembros, carentes de formación y sobrados de servilismo ante el Obispo. Consecuencia de esto era la indiferencia de los sacerdotes hacia todo lo que pudiera salir de la Curia, justa respuesta a la desconfianza que la Curia sentía respecto de los sacerdotes ${ }^{36}$.

\section{BIBLIOGRAFÍA}

I. Fuentes

1. Archivos particulares:

a. Benjamín DOMTNGUEZ: Informe confidencial al Nuncio, 21-VI-1968 (INCO); Informe de seglares al Nuncio, 1970 (INSE); Informe al Cardenal Prefecto de la Sagrada Congregación de Enseñanza y Catequesis, 15-V-1971 (INCAR); Informe sobre el Instituto de San Isidoro de León (España), 27-II-1970 (INFISSI); Carta de la Cancillería-Secretaría del Obispado de León a Eladio Fernández, 28-I-1970; Escrito al Nuncio, 29-I-1970; Carta de un grupo de sacerdotes al Gobernador Civil de León, 10-XI-1976; Carta del Magistral al Vicario y al clero de la Diócesis, 31-I- y 22-II-1971; Carta del Delegado Diocesano de Enseñanza al Magistral, 4-II-1971.

b. Eladio FERnÁNDEZ: Comunicado al Obispo, 22-I-1970; Carta del Obispo de León a Eladio Fernández, 2-II-1970.

b. J. Francisco FONTECHA: Estudio informativo sobre la situación actual de la diócesis de León, 11-VIII-1968 (ESTIN).

2. Archivo General de la Administración (AGA). Caja 567.

II. Publicaciones periódicas:

Boletín Oficial del Obispado de León (BOOL).

Diario de León.

${ }^{36}$ INCO, 1968, p. 18.

Actas del I Congreso de Historia de la Iglesia y el Mundo Hispánico

Hispania Sacra, 52 (2000) 
III. BRLIOGRAFIA:

A. Álvarez Bolado: El experimento del nacional-catolicismo (1939-1975), Edicusa, Madrid, 1976.

F. BLÁZQUEZ: La traición de los clérigos en la España de Franco, Trotta, Madrid, 1991.

G. FERNÁNDEZ: Religión y poder. Transición en la Iglesia española, Edilesa, León, 1999.

J. GuERRA CAMPos: «La Iglesia en Espafia (1936-1975). Sintesis histórica», en Boletín Oficial del Obispado de Cuenca, 5-V-1986.

J. GUERRA CAMPos: Crisis y conflicto de la Acción Católica Española y otros órganos nacionales de apostolado seglar desde 1964, Aude, Madrid, 1989.

J. Georgel: Le Franquisme, Histoire et Bilan 1936-1969, Seuil, Paris ,1970.

F. MONTERo: «Crónica de las XVI Jomadas Nacionales de presidentes diocesanos de la JACE», en TUSELl, A. ALTED, J. MATEOS (eds.): La oposición al régimen de Franco, UNED, Madrid, 1990.

F. MONTERO: «Juventud y política. Los movimientos juveniles de inspiración católica en Españan, Studia Historica, 5, 1987, pp. 105-121.

A. MURCIA: Obreros y obispos en el franquismo, HOAC, Madrid, 1995.

V. PÉREZ DfAZ: La primacia de la sociedad civil, Alianza, Madrid, 1993.

J.-J. RuIz Rico: El papel de la Iglesia Católica en la España de Franco, Madrid, 1977.

F. URBINA: Iglesia y sociedad en España (1939-1977), Popular, Madrid, 1977. 